\title{
The Relationship between Moral Emotions of Shame, Guilt, and Moral Identity among Undergraduate Students in Indonesia
}

\section{Eva Septiana*}

Department of Educational Psychology, Faculty of Psychology, Universitas Indonesia, Depok,

*Corresponding Author:

Eva Septiana

Educational Psychology Department

Faculty of Psychology, Universitas Indonesia

Jl. Lkr. Kampus Raya, Depok, Jawa Barat

Indonesia, 16424

Tel.: +62 217270004

E-mail: evaseptiana.septiana@gmail.com 


\title{
The Relationship between Moral Emotions of Shame, Guilt, and Moral Identity among Undergraduate Students in Indonesia
}

\begin{abstract}
Previous research on moral emotion and moral identity was conducted particularly on guilt in the field of sports. However, the moral emotions do not include shame and guilt, which were important in investigating the relationship between moral emotions, such as shame and guilt, and moral identity. Thus, the purpose of this study was to examine the relationship of shame and guilt with moral identity. Participants are 520 undergraduate students from all over Indonesia. The participants accomplished the Moral Identity Questionnaire and the Test of Self-Conscious Affect-3 questionnaire. The results showed that the moral emotions of shame and guilt were associated with moral identity, but the moral emotion of shame embodied a stronger influence on moral identity. The study results show that the moral emotions of shame and guilt have a positive correlation with moral identity. The results of this study showed different results in Western culture, where moral guilt was associated with moral identity. The implications of this study are the need for parents and teachers to develop guilty moral emotions because the impact of these moral emotions is more constructive and can encourage individuals to engage in moral action. The results show that with higher moral emotions of guilt, moral identity decreases. The results of this study indicate the need for further research on the factors that affect the moral identity of undergraduate students in Indonesia.
\end{abstract}

Keywords: guilt as moral emotion, shame as moral emotion, moral identity, undergraduate students

\section{Introduction}

Undergraduate students as higher education learners are exposed to morality from their community and educational system over long periods of time. The age range of undergraduate students (around 18-22 years) represents an advanced stage of moral reasoning (Papalia \& Feldman, 2012). According to Nather (2013), undergraduate students have higher scores in moral reasoning compared with non-students and other individuals in lower grades.

Although individuals, particularly undergraduate students, have advanced moral reasoning, their behavior is not always consistent with morality. According to Blasi (1983, in Hardy \& Carlo, 2005), every individual has his/her own belief in the importance of morality for himself/herself. The belief is called moral identity; it is the belief in acting in accordance with one's morals and understanding the importance of these morals in forming the character of a person (Blasi, 1983, in Hardy \& Carlo, 2005).

An undergraduate student is presupposed to have a moral identity because based on the psychosocial approach by Erikson (1978), students should have passed the phase of identity formation in adolescence. Nevertheless, Blasi (1983, as cited in Hardy, 2006) states that only a developing subjective identity can activate a sense of responsibility to act consistently with what is believed. Subjective identity consists of individual experiences (Hardy, 2006). In this context, subjective identity contains the individualized moral experience of the person that becomes unified and becomes an important value to be realized. Therefore, students whose subjective 
identity is not developed have a tendency to perform actions that are not in accordance with their identity.

Based on the preceding statement, moral identity does not always guarantee whether an individual can align his moral reasoning with his actions. Therefore, another aspect is needed which can connect moral reasoning and moral action. To act in accordance with morality, every individual needs to experience moral emotions that can increase the individual's sensitivity to the moral issues in his/her environment. This argument is supported by Haidt (2003) who states that moral emotions are related to the interests and welfare of others. Moral emotions are also considered as the main source of motivation for doing good and moral action (Hoffman, 2000, as cited in Hardy, 2006; Huebner, Dwyer, \& Hauser, 2009; Kohlberg \& Hersh, 1977; Kroll \& Egan, 2004, as cited in Tangney et al., 2007; Lickona, 1976). Undergraduate students in the previous case indicated that they were not yet able or unable to be sensitive to the welfare and rights of the victim such that their actions violate the rights and welfare of the victim. The researcher believes that based on the aforementioned moral-emotional exposure, moral emotion also has an important role in connecting moral reasoning with moral action.

\section{Moral Emotions of Shame and Moral Identity}

According to Tracy and Robins (2004), self-conscious emotions, including shame, contribute to individual identity. Furthermore, self-conscious emotions are experienced by individuals when their identities are threatened or affected by interpersonal situations. The emergence of selfconscious emotions helps individuals to uplift and protect their identity (Tracy \& Robins, 2004). For example, when an individual in a particular situation is threatened by his/her mistake, shame appears to protect his/her identity by motivating the individual to elicit a particular behavior.

Moral emotions of shame have a role in the formation of individual identities (Czub, 2013). According to Czub (2013), the moral emotion of shame is evaluative in nature, providing feedback in the form of consequences that affect individual views and commitment to internal and external values, including morals adopted by individuals. The individual will reconstruct his/her identity when he/she finds that his/her values or behavior are inconsistent with the environment and morals, or fail to meet the existing environmental and moral demands. The negative aversion in moral emotions of shame is a sign that individual behavior is inconsistent with environmental and moral demands. The emergence of shame as a moral emotion affects the phase of exploration and commitment to identity formation (Czub, 2013). Moral identity as part of identity is also reconstructed as individuals construct their identity.

The ability to feel shame is assumed to be the variable that connects moral emotion with the formation of identity (Czub, 2013). In individuals capable of adaptive shame and characterized by high tolerance of shame, moral emotion of shame has a constructive role in identity formation (Czub, 2013). In individuals who perform maladaptive shame regulation and characterized by a low tolerance for shame, the formation of identity becomes impaired. Czub (2013) concludes that the tendency to experience a moderate level of shame and adaptive shame helps the formation of individual identities. Considering previous research, a hypothesis can be made that a positive correlation exists between the moral emotion of shame and moral identity. 


\section{Moral Emotions of Guilt and Moral Identity}

According to Tangney, Stuewig, and Mashek (2007), moral emotions can provide immediate feedback when the individual takes action. Feedback is the response generated by moral emotions. Therefore, feedback on each emotion may differ. Feedback caused by guilt is said to be more positive than shame. Guilt can trigger constructive action. The point is that when guilty moral emotions arise before or after an action, the individual is likely to take actions that pay more attention to the welfare of others. Therefore, guilty moral emotions can be considered as those that are important to appear consistently in each individual.

If the guilt moral emotion arises consistently, then they can crystallize into the individual's moral identity. It has been widely known that identity is a construct that does not stand alone but is the result of the integration of many things. Moral emotions, especially guilt, can function well as a complementary component of identity, especially moral identity. Moral identity and moral emotion can be said to have a similar role in helping moral reasoning to be a more concrete form. Both are equally considered to bridge the gap between moral reasoning and moral action. Moral identity is known to have a relationship with actions that are considered good. Research has proved that individuals who have a moral identity will avoid actions that harm others (Kavussanu, Stanger \& Ring, 2015)., Both moral identity and emotion can be a reinforcement of the emergence of good action. Thus, we can assume that moral emotions (especially guilt) and moral identity exist in one individual; the possibility for an individual to do good therefore increases. If a person judges that harm done to another person is incompatible with his/her identity and gives rise to feelings of guilt, then he/she will try to avoid actions that are harmful to others.

Moral identity and guilt have similar characteristics. Both arise from within an individual. According to Tangney, Stuewig, and Mashek (2007), guilt is a self-centered emotion. The point is self-centered evaluation and does not consider anything outside of the individual. Similarly, moral identity processes all its components based on internal decisions and no other aspects outside the individual self. The similarity between the two can be a strengthening of the relationship because if they are united, then the internal drive within the individual to perform good actions increases. From this, I expect a positive correlation between guilt moral emotions and moral identity.

\section{Methods}

\section{Participants}

The study involved 520 undergraduate students in Indonesia (379 females and 141 males). The age of the participants ranged from 17 to 24 years old $(M=20.45, S D=1.237)$. The majority of the study sample $(33.2 \%, \mathrm{~N}=520)$ was 21 years old. The majority of the research sample tribe is Java with percentage of $38.8 \%, N=520$. In this study, sampling technique was convenience sampling that belonged to non-probability sampling. Prior to data collection, the participants were requested to fill out a set of demographic questions, including age, to provide general information about themselves. 


\section{Research Design}

Correlation analysis and multiple regression were conducted to examine the relationship of moral emotion, consisting of shame and guilt, and moral identity.

\section{Measures}

The following research instruments were applied in the present study:

Moral Identity Measurement. The Moral Identity Questionnaire (MIQ) by Black and Reynolds (2016) was used to measure moral identity. MIQ consists of two subscales, each corresponding to moral self and moral integrity. The questionnaire consisted of 20 MIQ items with a six-point Likert scale ranging from sangat tidak sesuai (strongly disagree) to sangat sesuai (strongly agree). The possible score range that can be obtained is 20-120, with 70 as the middle score.

Measure Test of Self-conscious Affect-3. The Test of Self-Conscious Affect-3 (TOSCA-3) by Tangney and Dearing (2002) was used to measure shame. TOSCA-3 that has been adapted to Bahasa (Indonesian) by Barlian (2013) consists of 17 scenarios under four categories: family, friendship, occupational, and self. These scenarios are followed by 34 items measuring shame and guilt. However, in this study, only 16 items measuring shame were used. The choice of answers is presented in a five-point Likert scale ranging from tidak sesuai (disagree) to sangat sesuai (strongly agree). The possible score range that can be obtained is 16-80, with 48 as the middle score.

\section{Procedure}

Both measuring instruments were combined and arranged in the form of offline and online questionnaires. Official questionnaires were provided to participants around Jakarta, while online questionnaires were distributed through the internet to all areas of Indonesia to quickly obtain participants according to the quota. Once the participant quota was met, the online form was closed. The participants received mobile phone credit as compensation.

\section{Data Analysis}

First, descriptive statistical analysis was conducted to obtain the analysis for demographic data. Then, we conducted multiple regression using SPSS to observe the relationship between moral identity and moral emotions of shame and guilt.

\section{Results}

The results consisted of sample means, standard deviations, and range of age, shame, guilt, and moral identity.

Table 1

Descriptive Statistics for Age, Shame, Guilt, and Moral Identity

\begin{tabular}{lcccc}
\hline & Mean & SD & Min & Max \\
\hline Age & 20,45 & 1,237 & 17 & 24 \\
Shame & 51,17 & 10,14 & 16 & 79 \\
Guilt & 67,92 & 8,529 & 39 & 97 \\
Moral Identity & 94,45 & 8,13 & 66 & 115 \\
\hline
\end{tabular}

Statistical analysis using Pearson's correlation was performed to examine the relationship between shame variables and moral identity. Result analysis using SPSS software shows a 
correlation value of 0.149 and significant on $\operatorname{LoS} 0.01, \mathrm{r}(518)=0.149, \mathrm{p}<0.01$. Based on these results, a significant relationship exists between shame and moral identity in undergraduate students in Indonesia.

The calculation of Pearson correlation found that a significant relationship exists between guilt variables and moral identity. Result analysis using SPSS software shows a correlation value of 0.502 and significant on LoS $0.05, \mathrm{r}(518)=0.502, \mathrm{p}<0.05$. Thus, we can conclude that the higher the moral identity of an individual, the higher is the guilt perceived by him/her. This result means that the more one feels guilt, the more intense is the process of understanding what is good and bad; thus, the person works harder to act in a manner consistent with that understanding.

Table 2

Correlations of Shame, Guilt, and Moral Identity

\begin{tabular}{lll}
\hline & & Moral Identity \\
\hline Shame & Pearson Correlation & $0.149 * *$ \\
& Sig. (two-tailed) & 0.001 \\
Nuilt & Pearson Correlation & 520 \\
& Sig. (two-tailed) & $0.0502 *$ \\
N & 0.001 \\
\hline *Correlation is significant at the 0.05 level (two-tailed) & 520 \\
$* *$ Correlation is significant at the 0.01 level (two-tailed) &
\end{tabular}

Multiple regression analysis was used to test if the moral emotions significantly predicted moral identity. The results of the regression indicated that the predictors (shame and guilt) explained $21 \%$ of the variance $\left(\mathrm{R}^{2}=0.38, \mathrm{~F}(2,62)=6,244, \mathrm{p}<0.02\right)$. Furthermore, the moral emotion of shame significantly predicted moral identity $(\beta=0.077, \mathrm{p}<0.001)$ as did guilt $(\beta=-0.115, \mathrm{p}<$ 0.001).

\section{Discussion}

Moral identity is an important aspect of the formation of behaviors that conform to moral values. On the one hand, the moral identity of the individual is the belief that motivates him/her to behave according to moral standards. On the other hand, moral emotions are emotions that motivate individuals to behave according to moral standards.

Based on these definitions, moral identity and moral emotions are assumed to have a relationship because they have the same role in connecting moral standards with individual moral behavior. With regard to the moral emotion of shame, individuals who feel it are more focused on selfassessment as a whole (i.e., the global self). The result of this study shows that moral emotions of shame have a greater influence on moral identity than moral emotion of guilt. Smith, Webster, Eyre, and Parrott (2002) assert that shame emotions are an effective reaction followed by the response of others due to public exposure. Experiencing shame is desired because it gives individuals a source of self-evaluation. This individual self-evaluation can be drawn from the evaluation provided by others (Tangney et al., 2007). The collective Indonesian culture causes the individual to be fully aware of himself based on the recognition of others. Individuals feel the moral emotion of shame when caught performing actions that are not in accordance with the 
moral values prevailing in society. This idea explains the relationship between the moral emotion of shame and moral identity of an undergraduate in Indonesia.

Tangney, Stuewig, and Mashek (2007) argue that guilt moral emotions can be adaptive emotions, which make the individual who feels the emotion likely to engage in curative or reparative behavior from what was previously considered as misconduct. Moreover, individuals who have moral identity will strive to apply moral values in their daily life. According to the results of this study, the moral emotions of shame and guilt together affect the moral identity. In theory, the moral emotions of shame and guilt have a relationship with moral identity because it emphasizes the formation of self-conscious emotions and moral identity that emphasizes the formation of the self.

The results of this study also show that the correlation between moral identity and moral emotions of shame and guilt is fairly weak and only $2.1 \%$ of moral identity variables can be explained by the moral emotions of shame and guilt, while $97.9 \%$ is explained by other variables. The concept of moral identity in Indonesia has not been studied extensively. Therefore, further research can examine the factors that influence the moral identity of Indonesians other than moral emotions.

Other research results indicate that any addition of guilt moral emotions would reduce the moral identity. This finding means that high moral emotion of guilt would further weaken the moral identity of the individual. These results are different from research findings in the West. Empirically, the relationship of moral emotion and moral identity has been studied by Kavussanu, Stanger, \& Ring (2015), who examined antisocial behavior in sports. The study focused on the moral emotions of shame and guilt. The study found that the rise of antisocial behavior was influenced by the moral identity of the individual when mediating guilt moral emotions (Kavussanu, Stanger, \& Ring, 2015).

When morality becomes an important and central part of a person's self-identity, the person will have a strong drive to behave in a moral way (Hardy and Carlo, 2011). The basis for the formation of a guilt moral emotion is empathy, in which the individual is able to put himself in another person's place so as to feel and think as others do. Therefore, individuals feel guilty and uncomfortable when performing actions that can harm others. If a relationship exists between guilt moral emotions and moral identity, then the individual emphasizes the importance of behaving in accordance with the moral values that become his identity. The moral emotion of guilt is a concern that continues to be developed through parenting and education from elementary to college.

This study has several limitations. These limitations may be the different perceptions of the concept of guilt between Eastern and Western culture, but the measuring instruments used are TOSCA-3 measurements adapted from Western research. The concept of shame and guilt on the TOSCA-3 instrument is still poorly understood by Indonesian students. According to Breugelmans and Poortinga (2006), Javanese people have a characterization of guilt that is different from that of Western culture. This condition indicates the importance of understanding guilt as a moral emotion in a larger, more representative sample of the Indonesian student population. 
Moreover, the moral emotion of shame is different between Western and Eastern cultures. Breugelmans \& Poortinga (2006) examined the emotion of shame in Javanese participants and found that their expression of shame differs from that of people from other countries. Thus, exploring the moral emotions of shame in accordance with Eastern culture is important. The findings of this study are expected to lead to further research on the moral emotion of shame in Eastern culture.

\section{References}

Breugelmans, S. M., \& Poortinga, Y. H. (2006). Emotion without a word: Shame and guilt among Raramuri Indians and rural Javanese. Personality Processes and Individual Differences, 9(6), 1111-1122.

Black, J. E., \& Reynolds, W. M. (2016). Development, reliability, and validity of the Moral Identity Questionnaire. Personality and Individual Differences, 97, 120-129.

Barlian, I. Y. (2103). Perbedaan Emosi Malu dan Emosi Bersalah pada Generasi Tua dan Generasi Muda. [Thesis]. Universitas Indonesia- Depok, Indonesia.

Czub, T. (2013). Shame as a self-conscious emotion and its role in identity formation. Polish Psychological Bulletin, 44(3), 245-253.

Gravetter, F. J., \& Wallnau, L.B. (2013). Statistics for the Behavioral Sciences. (9 ${ }^{\text {th }}$ ed.). Canada: Wadsworth.

Haidt, J. (2003). The moral emotions. In R.J. Davidson, K.R. Scherer \& H.H. Goldsmith (Eds.), Handbook of affective sciences. Oxford: Oxford University Press.

Hardy, S.A. (2006). Identity, reasoning, and emotion: An empirical comparison of three sources of moral motivation. Motivation and Emotion, 30(3), 207-215.

Hardy, S. A., \& Carlo, G. (2011). Moral identity: What is it, how does it develop, and is it linked to moral action?. Child Development Perspectives, 5(3), 212-218.

Hardy, S.A. \& Carlo, G. (2005). Identity as a source of moral motivation. Human Devel-opment. Available on doi:10.1159/000086859.

Huebner, B., Dwyer, S., \& Hauser, M. (2009). The role of emotion in moral psychology. Trends in cognitive sciences, 13(1), 1-6. Downloaded in June 2016 from http://pages.stolaf.edu/psych-391spring15/files/2014/02/huebner.pdf.

Kavussanu, M., Stanger, N., \& Ring, C. (2015). The effects of moral identity on moral emotion and antisocial behavior in sport. Sport, Exercise, and Performance Psychology, 4(4), 268-279.

Kohlberg, L., \& Hersh, R.H. (1977). Moral development: A review of the theory. Teory into practice, 16(2), 53-59.

Lickona, T. (1976). Research on Piget's theory of moral development. In T. Lickona (Ed.), Moral Development and Behavior (198-218). USA: Holt, Rinehart, \& Winston.

Nather, F. (2013)., Exploring the impact of formal education on the moral reasoning abilities of college students. College Student Journal, 47 (3), 470-477.

Papalia, D. E., \& Feldman, R. D. (2012). Experience Human Development. (12 ${ }^{\text {th }}$ ed.). New York: McGraw-Hill.

Smith, R. H., Webster, J. M., Parrot, W. G., \& Eyre, H. L. (2002). The role of public exposure in moral and nonmoral shame and guilt. Journal of Personality and Social Psychology, 83(1), 138-159. doi: 10.1037//00223514.83.1.138.

Tracy, J. L., \& Robins, R. W. (2004). Putting the self into self-conscious emotions: a theoretical model. Psychol. Inq., 15:103-125

Tangney, JP., Wagner P., Gramzow R. (1989). The Test of Self-Conscious Affect (TOSCA). Fairfax, VA: George Mason University.

Tangney, J. P., Stuewig, J., Mashek, D.J. (2007). Moral emotions and moral behavior. Annual Review Psychology, 58, 345-372. Doi: 10.1146/annurev.psych.56.091103.070145. 